\title{
Feasibility of performing esophageal endoscopic submucosal dissection using master and slave transluminal endoscopic robot
}

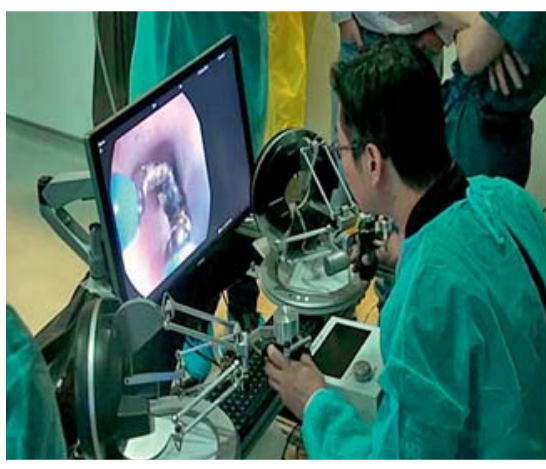

- Fig. 1 Esophageal endoscopic submucosal dissection (ESD) being performed using the newly developed MASTER endoscopic platform.

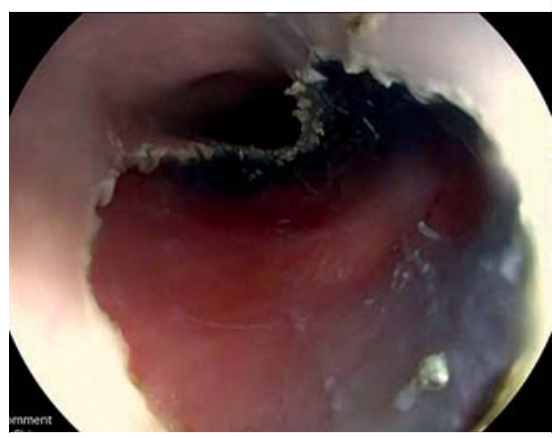

- Fig. 2 Endoscopic view of the postendoscopic submucosal dissection (ESD) ulcer.

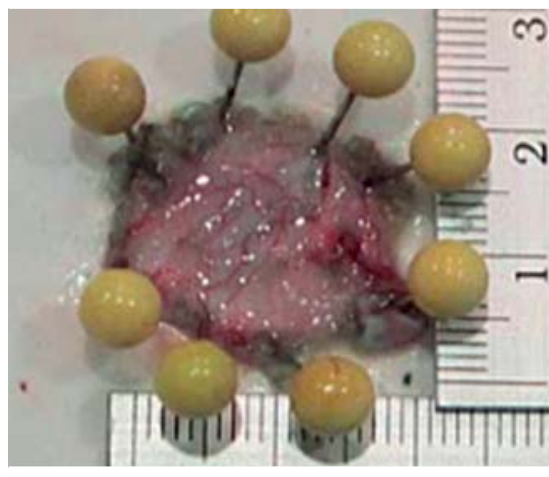

- Fig. 3 The resected specimen, which measured $20 \times 20 \mathrm{~mm}$.
The feasibility of endoscopic submucosal dissection (ESD) using the master and slave transluminal endoscopic robot (MASTER) has been shown in our previous studies [1-3]. Compared with gastric ESD, esophageal ESD remains challenging because of technical difficulties and risks $[4,5]$. The aim of this study was to evaluate the feasibility of using MASTER to perform esophageal ESD.

The new version of MASTER was used for esophageal ESD on one pig. The MASTER was redesigned to facilitate performance of ESD within a narrow working space. The main outcomes were: operating time, completeness of resection, and adverse events. The secondary outcomes included: clearance of operative field and limitation of robot arm manipulation in the narrow working space, assessed by counting the number of episodes of blind cutting. For the purpose of comparison with esophageal ESD, one gastric and one colonic ESD were performed by the same operator.
All procedures were successfully completed ( $>$ Table 1; $>$ Figs. 1 - 3; \Video 1). It took 15,63 , and 45 minutes to complete the esophageal, gastric, and colonic ESDs, respectively. All lesions were excised en bloc; the specimen sizes were: $20 \times 20,50 \times 45$, and $35 \times 35 \mathrm{~mm}$, respectively. The dissection speeds were: 20.9 , 28.0 , and $21.4 \mathrm{~mm}^{2} / \mathrm{min}$, respectively. There were no adverse events. The number of episodes of blind cutting were: 2 , 6 , and $6(0.13,0.10$, and $0.13 / \mathrm{min})$.

In contrast to gastric and colonic ESD, the traction of the grasper during esophageal ESD tended to align with the long axis because of the narrow working space. There was no difference comparing esophageal against gastric and coIonic ESD in terms of the speed of dissection, the rate of complete resection, the occurrence of adverse events, and the number of episodes of blind cutting. In conclusion, performing esophageal ESD using the MASTER was feasible with a certain degree of adjustment for the narrow working space.

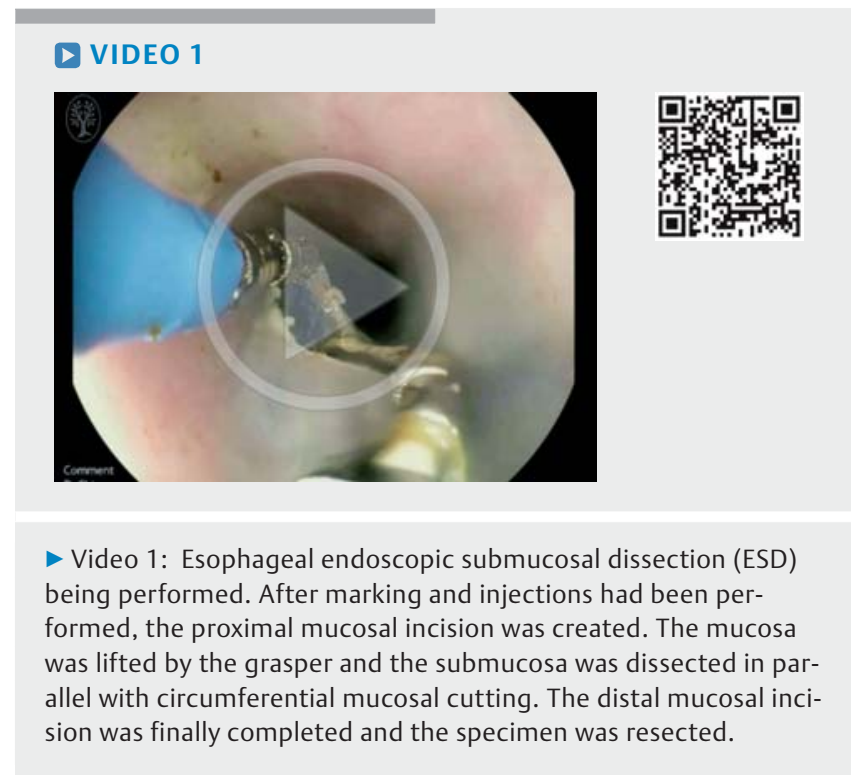


Table 1 Outcomes of endoscopic submucosal dissection procedures using the MASTER.

\begin{tabular}{|l|l|l|l|}
\hline & Procedure $\mathbf{1}$ & Procedure 2 & Procedure 3 \\
\hline Organ & Esophagus & Stomach & Colon \\
\hline Location & Middle thoracic & $\begin{array}{l}\text { Middle greater } \\
\text { curvature }\end{array}$ & Sigmoid \\
\hline Completion & Complete & Complete & Complete \\
\hline Operation time, minutes & 15 & 63 & 45 \\
\hline Size of specimen, $\mathrm{mm}$ & $20 \times 20$ & $50 \times 45$ & $35 \times 35$ \\
\hline Dissection speed, $\mathrm{mm} \mathbf{m}^{2} / \mathrm{min}$ & 20.9 & 28 & 21.4 \\
\hline En bloc/piecemeal & En bloc & En bloc & En bloc \\
\hline Uncontrolled bleeding & No & No & No \\
\hline Perforation & No & No & No \\
\hline Episodes of blind cutting & 2 & 6 & 6 \\
\hline
\end{tabular}

Endoscopy_UCTN_Code_TTT_1AO_2AG

The Authors

\section{Competing interests}

P.W.Y. Chiu served on the scientific advisory board of EndoMaster Pte Ltd. S.J. Phee and K. Y. Ho are cofounders of EndoMaster Pte Ltd.
Nobuyoshi Takeshita ${ }^{1}$, Khek Yu Ho${ }^{2}$, Soo Jay Phee $^{3}$, Jennie Wong', Philip Wai Yan Chiu ${ }^{4}$

1 Department of Medicine, National University of Singapore, Singapore

2 Yong Loo Lin School of Medicine, National University of Singapore, Singapore

3 School of Mechanical and Aerospace Engineering, Nanyang Technological University, Singapore

4 Department of Surgery, The Chinese University of Hong Kong, Hong Kong
Corresponding author

Nobuyoshi Takeshita, MD, PhD

Department of Medicine, National University of Singapore, 1E Kent Ridge Road NUHS Tower Block, Level 10 University Medicine Cluster, Singapore 119260, Singapore Fax: +65-67724361

ntakeshita1225@gmail.com

\section{References}

[1] Wang Z, Phee SJ, Lomanto D et al. Endoscopic submucosal dissection of gastric lesions by using a master and slave transluminal endoscopic robot: an animal survival study. Endoscopy 2012; 44: 690-694

[2] Phee S], Reddy N, Chiu PW et al. Robotassisted endoscopic submucosal dissection is effective in treating patients with earlystage gastric neoplasia. Clin Gastroenterol Hepatol 2012; 10: 1117-1121

[3] Ho KY, Phee S], Shabbir A et al. Endoscopic submucosal dissection of gastric lesions by using a Master and Slave Transluminal Endoscopic Robot (MASTER). Gastrointest Endosc 2010; 72: $593-599$

[4] Tanaka S, Morita Y, Fujita T et al. Ex vivo pig training model for esophageal endoscopic submucosal dissection (ESD) for endoscopists with experience in gastric ESD. Surg Endosc 2012; 26: 1579-1586

[5] Sato $H$, Inoue $H$, Ikeda $H$ et al. Clinical experience of esophageal perforation occurring with endoscopic submucosal dissection. Dis Esophagus 2014; 27: 617-622

\section{Bibliography}

DOI http://dx.doi.org/10.1055/s-0042-121486 Endoscopy 2017; 49: E27-E28

(c) Georg Thieme Verlag KG

Stuttgart $\cdot$ New York

ISSN 0013-726X 